(2) Open Access Full Text Article

\title{
Iron chelation therapy in transfusion-dependent thalassemia patients: current strategies and future directions
}

This article was published in the following Dove Press journal:

Journal of Blood Medicine

17 June 2015

Number of times this article has been viewed

\author{
Antoine N Saliba \\ Afif R Harb \\ Ali T Taher
}

Department of Internal Medicine, Division of Hematology/Oncology, American University of Beirut, Beirut, Lebanon
Correspondence: Ali Taher Building 56, Naef K Basile Cancer Institute, 5th floor, American University of Beirut Medical Center, Cairo Street, PO Box I I-0236, Riad El Solh II 07 2020, Beirut, Lebanon

Tel +96I I 350000 ext 5392

Email ataher@aub.edu.lb

\begin{abstract}
Transfusional iron overload is a major target in the care of patients with transfusiondependent thalassemia (TDT) and other refractory anemias. Iron accumulates in the liver, heart, and endocrine organs leading to a wide array of complications. In this review, we summarize the characteristics of the approved iron chelators, deferoxamine, deferiprone, and deferasirox, and the evidence behind the use of each, as monotherapy or as part of combination therapy. We also review the different guidelines on iron chelation in TDT. This review also discusses future prospects and directions in the treatment of transfusional iron overload in TDT whether through innovation in chelation or other therapies, such as novel agents that improve transfusion dependence.
\end{abstract}

Keywords: thalassemia, transfusion-dependent thalassemia, iron overload, iron chelation therapy, transfusion

\section{Introduction}

The transfusion of packed red blood cells (pRBCs) is the cornerstone of treatment of many refractory anemias, whether congenital or acquired. These anemias include transfusion-dependent thalassemia (TDT), sickle-cell anemia, acquired red cell aplasia, Diamond-Blackfan anemia, myelodysplastic syndromes (MDS), myelofibrosis, and aplastic anemia. Patients with transfusional iron overload usually require iron chelation therapy (ICT) to help decrease the iron burden and to prevent and/or delay long-term complications associated with iron deposition in tissues. The burden of transfusional iron overload is associated with the frequency, volume, and duration of blood transfusion therapy. The complications resulting from untreated transfusional iron overload include hepatic dysfunction and failure, endocrinopathies, and cardiac dysfunction.

The theoretical necessity of iron chelation is based on the fact that iron absorption and excretion are balanced at about $1 \mathrm{mg} /$ day, commensurate with body iron requirements. ${ }^{1}$ Iron is used by erythrocytes for heme synthesis and by other body cells to meet metabolic needs. Excess iron is stored in hepatocytes and macrophages within a dynamic cycle of iron utilization and recycling. ${ }^{1}$ Macrophages play a central role in iron recycling by engulfing senescent erythrocytes and releasing heme-derived iron into the plasma. ${ }^{2}$ However, the body does not have any mechanism to excrete excess transfusional iron that, for example, amounts up to $0.3-0.6 \mathrm{mg} / \mathrm{kg} / \mathrm{day}$ in TDT, assuming a transfusion rate of 2-4 units per month with $200-250 \mathrm{mg}$ of iron per unit. ${ }^{3}$ 
In this review, we discuss: 1) the diagnosis and assessment of transfusional iron overload in TDT; 2) the available treatment modalities, whether monotherapy or combination therapy; and 3) how treatment is initiated and subsequently modified with patient follow-up. The review also includes an overview of 4) future directions in treating transfusional iron overload in TDT.

The efficacy and pharmacological profile of the three approved iron chelators, deferoxamine (DFO), deferiprone (DFP), and deferasirox (DFX), are discussed. The characteristics of DFO, DFP, and DFX are summarized in Table 1. It is noteworthy that most of the data concerning the management of transfusional iron overload emanate from the thalassemia population with extrapolation to other diseases, although differences do exist.

\section{Overview of the pathophysiology of iron overload}

When red blood cells senesce, transfused red cells are phagocytized by reticuloendothelial macrophages where the hemoglobin is digested and the iron is freed from the heme. With a continuous increase in the iron load because of frequent transfusions, the excess iron in the cytosol of the macrophages starts spilling out into the plasma where transferrin binds the released iron. ${ }^{4}$ However, as transferrin is increasingly saturated with iron, iron storage in hepatocytes starts. As the storage capacity of the hepatocytes and the macrophages gets saturated, circulating iron surmounts the binding capacity of transferrin. Therefore, non-transferrinbound-iron (NTBI) starts circulating in the plasma and is deposited in cardiac myocytes, hepatocytes, pituitary cells, and pancreatic cells. ${ }^{5}$ Reactive oxygen species produced by the metabolism of NTBI play a central role in inducing cellular dysfunction, apoptosis, and necrosis. ${ }^{5}$ Figure 1 summarizes the interaction between the storage iron pool and the functional iron pool. Figure 2 depicts the role of NTBI in transfusional iron overload.

Iron distribution is modulated by the synthesis of hepcidin, a hepatic peptide, whereby increased hepcidin synthesis decreases iron release from enterocytes, hepatocytes, and macrophages through binding to ferroportin, the iron exporter, and causing its internalization. ${ }^{6,7}$ Even though ineffective erythropoiesis is significantly improved by transfusions in TDT, hepcidin suppression might contribute to iron overload, especially later in the transfusion-to-transfusion intervals. It has been suggested that the production of growth differentiation factor 15 (GDF15) and possibly other proteins, such as twisted-gastrulation 1 (TWSG1), contributes to the inhibition of hepcidin synthesis and thus promotes iron absorption despite systemic iron overload. ${ }^{8,9}$ Nevertheless, more recent studies argue against the role of GDF15 in hepcidin suppression. ${ }^{10,11}$ Kautz et al suggested that, upon erythropoietic stimulation, bone marrow and spleen erythroblasts increasingly produce erythroferrone, which, upon

Table I Characteristics of iron chelators in clinical use

\begin{tabular}{|c|c|c|c|}
\hline Characteristic & DFO & DFP & DFX \\
\hline $\begin{array}{l}\text { Route of } \\
\text { administration }\end{array}$ & $\begin{array}{l}\text { Subcutaneous } \\
\text { intravenous }\end{array}$ & Oral (tablets or solution) & Oral (dispersible tablet) \\
\hline Usual dose & $20-60 \mathrm{mg} / \mathrm{kg} /$ day over $8-24$ hours & $75-100 \mathrm{mg} / \mathrm{kg} /$ day in three divided doses & $20-40 \mathrm{mg} / \mathrm{kg} / \mathrm{day}$ \\
\hline Stoichiometry & Hexadentate $(I: I)$ & Bidentate $(3: 1)$ & Tridentate $(2: 1)$ \\
\hline Excretion & $\begin{array}{l}\text { Urinary } \\
\text { Fecal }\end{array}$ & Mainly urinary & Fecal \\
\hline Adverse effects & $\begin{array}{l}\text { Auditory } \\
\text { Ophthalmologic (retinal) } \\
\text { Reactions at site of infusion } \\
\text { Delay in bone growth } \\
\text { Yersinia infection }\end{array}$ & $\begin{array}{l}\text { Gastrointestinal } \\
\text { Neutropenia/agranulocytosis } \\
\text { Arthralgia } \\
\text { Increase in liver enzymes }\end{array}$ & $\begin{array}{l}\text { Gastrointestinal disturbances } \\
\text { Gastrointestinal bleeding } \\
\text { Increase in serum creatinine } \\
\text { Rash } \\
\text { Increase in liver enzymes } \\
\text { Liver failure } \\
\text { Renal insufficiency }\end{array}$ \\
\hline Advantages & Long-standing experience & $\begin{array}{l}\text { Most robust evidence on cardiac } \\
\text { siderosis improvement }\end{array}$ & Once-daily dosing, oral \\
\hline Disadvantages & Lack of compliance, parenteral & Frequent monitoring of CBC (weekly) & High cost \\
\hline $\begin{array}{l}\text { Licensed use } \\
\text { in transfusion- } \\
\text { dependent } \\
\text { anemias }\end{array}$ & $\begin{array}{l}\text { Treatment of chronic iron } \\
\text { overload resulting from } \\
\text { transfusion-dependent anemia }\end{array}$ & $\begin{array}{l}\text { In Europe, North America, and Asia: } \\
\text { treatment of iron overload in TM where } \\
\text { DFO is contraindicated or inadequate }\end{array}$ & $\begin{array}{l}\text { US: treatment of transfusional iron } \\
\text { overload in patients } 2 \text { years or older } \\
\text { Europe: treatment of transfusional iron } \\
\text { overload in TDT patients, } 6 \text { years and } \\
\text { older, and when DFO is contraindicated } \\
\text { and inadequate, for patients } 2-5 \text { years old }\end{array}$ \\
\hline
\end{tabular}

Abbreviations: DFO, deferoxamine; DFP, deferiprone; DFX, deferasirox; CBC, complete blood count; TM, thalassemia major; TDT, transfusion-dependent thalassemia. 


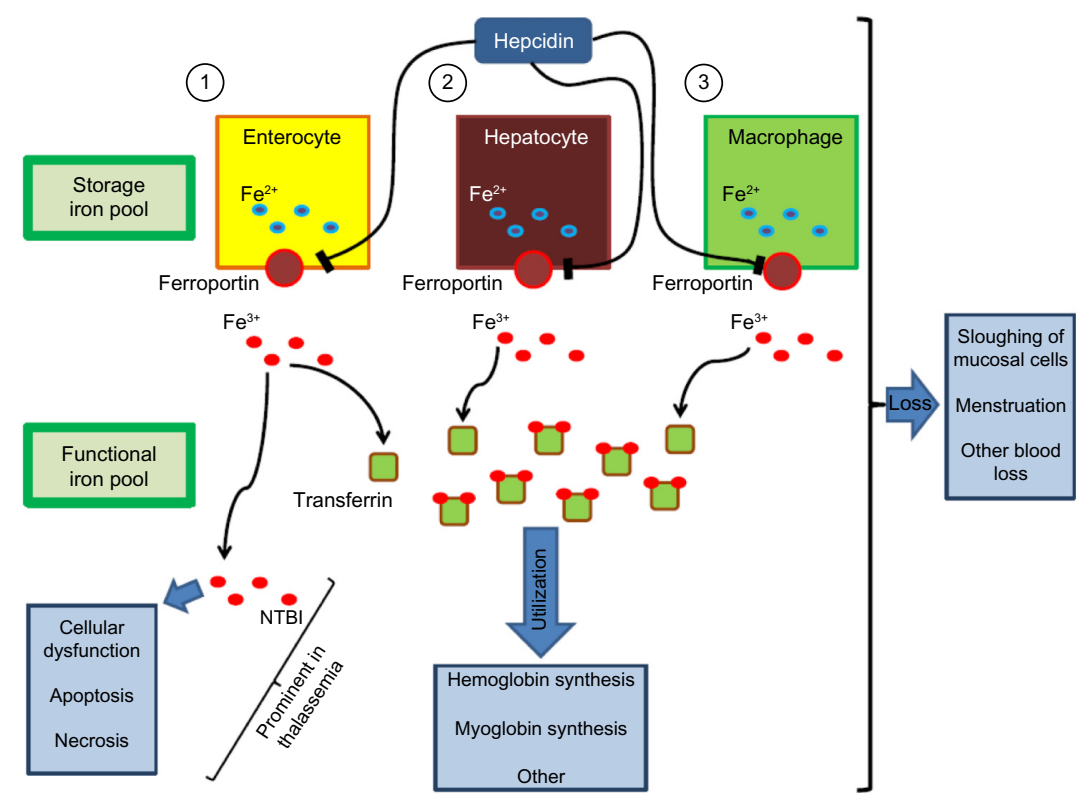

Figure I After absorption of iron into the enterocyte at the level of the duodenum, ferroportin transports iron into the circulation.

Notes: Under normal circumstances, transferrin carries nearly all serum iron collected from duodenal absorptive epithelium, macrophages, and hepatocytes. The liver peptide hepcidin binds ferroportin, causing its internalization and degradation, leading to a decrease in circulating iron. The functional iron pool is used for hemoglobin synthesis, myoglobin synthesis, and other functions. Iron losses happen due to menstruation, sloughing of mucosal cells, and other blood losses. The role of NTBI in causing cellular dysfunction, apoptosis, and necrosis is prominent in thalassemic disorders.

Abbreviation: NTBI, non-transferrin-bound-iron.

secretion into the circulation, directly acts on the liver to inhibit hepcidin production. ${ }^{12}$

\section{Overview of the iron chelating agents in use: characteristics and evidence Deferoxamine}

DFO is a hexadentate iron chelator that binds iron in $1: 1$ complexes. DFO cannot be orally absorbed; therefore, it is administered at a dose of $20-50 \mathrm{mg} / \mathrm{kg} /$ day, subcutaneously or intravenously. ${ }^{13}$ Higher doses up to $60 \mathrm{mg} / \mathrm{kg} /$ day have been used in patients with high body iron stores. Having a short plasma half-life of 20-30 minutes, DFO should be administered over a span of 8-10 hours a day, on 5-7 days a week. Given the pharmacokinetics of DFO, it does not provide 24-hour-long chelation of NTBI. ${ }^{14}$ DFO is excreted through biliary secretions and the urine. It is approved in the US, Canada, Europe, and other countries for transfusional iron overload. Only one randomized trial has compared chelation in 20 children with TDT with no therapy ( 10 were treated with DFO and 10 received no therapy). ${ }^{15}$ After a mean of 5.8 years of follow-up, the patients treated with DFO intramuscularly had a mean liver iron concentration (LIC) of $25.9 \mathrm{mg} / \mathrm{g}$ dry weight (dw) of liver tissue as compared to $42.2 \mathrm{mg} / \mathrm{g} \mathrm{dw}$ in the control group. In 1982, Modell et al suggested a survival benefit for thalassemia patients treated with $4 \mathrm{~g}$ or more of DFO weekly as, at 14 years, six deaths occurred in the control group compared to only one death in the treatment group. ${ }^{16}$ A large observational study at seven Italian centers, involving 977 patients with TDT, also suggested a survival benefit for DFO. ${ }^{17}$ The survival rate was found to be progressively increasing for every 5-year birth cohort since 1975, the year of introduction of DFO. ${ }^{17}$ Moreover, Brittenham et al followed 59 patients with TDT, treated with DFO, for 4-10 years or until death. ${ }^{18}$ Using a natural logarithm of the ratio of transfusional iron load to DFO use, they suggested that early chelation with DFO in an amount proportional to the transfusional iron load decreases hepatic iron concentration and helps safeguard against diabetes mellitus, cardiac disease, and earlier death in patients with TDT. The cardiac benefits of DFO in the context of transfusional iron overload were highlighted by Anderson et al and Davis and Porter, who showed, respectively, that higher doses of DFO up to $60 \mathrm{mg} / \mathrm{kg} /$ day can reduce cardiac iron load and reverse cardiac complications. ${ }^{19,20}$ The side effects of DFO include irritation at the infusion site, growth retardation, skeletal changes, and ocular and auditory disturbances. ${ }^{13,21,22}$ Symptoms of cutaneous irritation at the site of the infusion respond to local anesthetic or glucocorticoid creams. Respiratory distress syndrome has been also reported with very high intravenous doses in the context of acute iron intoxication. ${ }^{13,22}$ Patients treated with DFO should be followed 


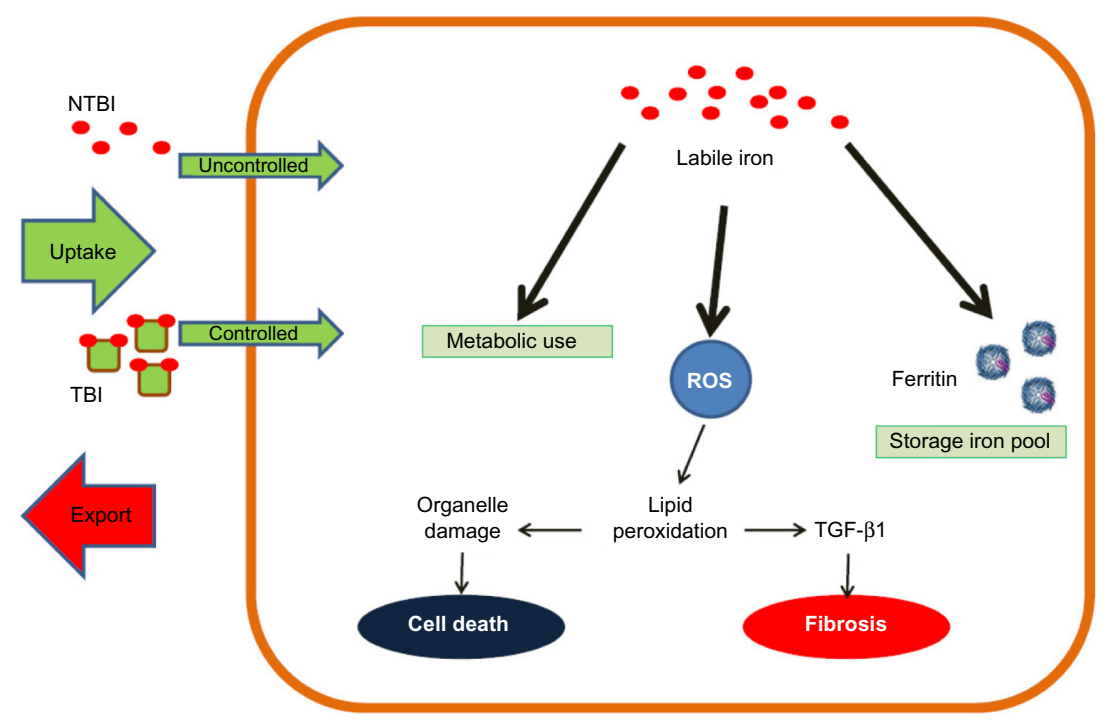

Figure 2 The excessive uncontrolled uptake of labile iron (NTBI) leads to iron overload in hepatocytes and cardiac myocytes.

Notes: Labile iron may be taken up by endocytosis; some of it is stored as ferritin. Excess labile iron may lead to the production of ROS that cause lipid peroxidation, organelle damage, and TGF- $\beta$ I production and result in cell death and fibrosis.

Abbreviations: NTBI, non-transferrin-bound-iron; ROS, reactive oxygen species; TBI, transferrin-bound-iron; TGF- $\beta$ I, transforming growth factor beta I.

up with yearly assessments of vision and auditory function. Pediatric patients treated with DFO should be monitored for growth delay by assessing body weight and growth every 3 months. ${ }^{13}$ Finally, limited compliance with DFO, due to the inconvenience of parenteral administration and its infectious complications, may lead to decreased efficacy in terms of iron chelation and progression of the manifestations of transfusional iron overload. ${ }^{23,24}$

\section{Deferiprone}

DFP, the first oral iron chelator to be used, is approved in Europe and other countries for transfusional iron overload in patients with TDT, when DFO therapy is contraindicated or inadequate. ${ }^{25}$ In the US, since October 2011, DFP is indicated for the treatment of adults with transfusional iron overload due to thalassemic disorders when chelation therapy with DFX or DFO is inadequate. ${ }^{26} \mathrm{DFP}$ is a bidentate iron chelator that forms 3:1 complexes, usually given at a dose of $75-100 \mathrm{mg} /$ $\mathrm{kg}$ /day divided over three doses. ${ }^{25}$ The lipophilicity of DFP enables this small molecule to gain access into myocytes. As previously mentioned, DFO therapy has been associated with improved survival of thalassemia patients, but cardiac complications remained the major cause of mortality. From this stemmed the interest in the possible benefits of DFP in reversing or preventing cardiac complications. BorgnaPignatti et al observed that DFP therapy was associated with significantly greater cardiac protection than DFO in thalassemic patients. ${ }^{27}$ Moreover, a retrospective study by Piga et al showed, through Kaplan-Meier analysis, that 5-year cardiac disease-free survival was significantly more favorable in thalassemic patients treated with DFP as compared to those treated with $\mathrm{DFO} .{ }^{28} \mathrm{~A}$ meta-analytic review of nine clinical trials showed that $75.5 \%$ of highly iron-overloaded patients, treated with DFP for at least 16 months at doses of $75 \mathrm{mg} /$ $\mathrm{kg}$ /day or higher, had a decrease in serum ferritin (SF) by an average of $23.5 \%$ from baseline..$^{29} \mathrm{~A} 1$-year randomized controlled trial involving 144 patients with TDT suggested that DFP $(75 \mathrm{mg} / \mathrm{kg} /$ day $)$ is as effective as DFO in the treatment of iron overload in TDT. ${ }^{30}$ Furthermore, higher doses of $100 \mathrm{mg} /$ $\mathrm{kg}$ /day were shown to be safe and efficacious in decreasing SF over 2 years in 12 patients with TDT. ${ }^{31}$ Compared to treatment with DFO, treatment with DFP was observed to be associated with lower myocardial iron deposition and higher left ventricular ejection fractions in a retrospective study by Anderson et al..$^{32}$ More robust prospective data from a randomized controlled trial of DFP versus DFO in 61 TDT patients with asymptomatic myocardial siderosis confirmed that, after 1 year of follow-up, the improvement in myocardial T2*, a method to quantitate cardiac iron load by MRI, was significantly greater in the DFP group. ${ }^{33} \mathrm{~A}$ retrospective study by Berdoukas et al also confirmed that monotherapy with DFP is effective in reducing cardiac siderosis. ${ }^{34} \mathrm{~A}$ retrospective study of a UK database of TDT patients suggested that DFP use is associated with a reduction in the risk of heart failure in patients with a baseline ejection fraction of $56-62 \%$ and in those with a normal ejection fraction of $63-70 \% .{ }^{35}$ Data from a large randomized controlled trial of 265 patients with TDT showed that DFP-containing regimens (DFP monotherapy, 
alternating DFO + DFP therapy, and combination therapy with DFO + DFP) were associated with a lower mortality when compared with DFO monotherapy. ${ }^{36}$ From a clinical standpoint, patients on DFP should be closely monitored as it may cause agranulocytosis and neutropenia necessitating weekly follow-up with complete blood count. ${ }^{25,37}$ DFP may also cause gastrointestinal disturbances, arthropathy, increased liver-enzyme levels, low plasma zinc level, and progression of hepatic fibrosis associated with increase in iron overload or hepatitis C. ${ }^{25,38}$ However, more recent studies have shown a lack of progression of liver fibrosis with DFP therapy. ${ }^{30,39-41}$

\section{Deferasirox}

DFX, a tridentate iron chelator that forms 2:1 complexes, is another oral agent with a once-daily dosing at a usual dose of $20-40 \mathrm{mg} / \mathrm{kg} /$ day. ${ }^{42}$ The plasma half-life of DFX is 16-18 hours, and it is predominantly excreted in biliary secretions. Just as DFO, it is approved in the US, Canada, Europe, and other countries for transfusional iron overload. ${ }^{42}$ In the context of DFP's potentially life-threatening side effect of agranulocytosis and its short half-life, DFX was developed out of a need for a long-acting chelator with a convenient dosing regimen for patients with transfusional iron overload. ${ }^{43}$ DFX should be taken on an empty stomach after dissolution in water, apple juice, or orange juice to assure adequate bioavailability. ${ }^{43,44}$ A Phase II trial randomized patients to DFX at $10 \mathrm{mg} / \mathrm{kg} /$ day or DFX at $20 \mathrm{mg} / \mathrm{kg} /$ day or DFO $40 \mathrm{mg} / \mathrm{kg}$ / day. ${ }^{45}$ It concluded that DFX was well tolerated and showed similar efficacy to DFO $40 \mathrm{mg} / \mathrm{kg}$ in terms of reducing LIC when used at $20 \mathrm{mg} / \mathrm{kg} /$ day. Moreover, Galanello et al evaluated the safety, tolerability, and pharmacokinetics of DFX in children 2 years or older. ${ }^{46}$ The study showed that DFX $10 \mathrm{mg} / \mathrm{kg} /$ day is well tolerated but does not induce a negative iron balance. Up to this date, the largest trial comparing DFX with DFO (study 0107, a Phase III trial) included 296 patients assigned to DFX and 290 patients assigned to DFO. ${ }^{47}$ The failure of this trial to prove non-inferiority was attributed to the underdosing of DFX. A total of $52.9 \%$ of the patients assigned to DFX had either a maintained or a reduced LIC at 1 year, while $66.4 \%$ of the patients in the DFO arm reached the primary endpoint. However, this trial, which included both pediatric and adult patients, suggested that DFX doses of $30 \mathrm{mg} / \mathrm{kg}$ led to negative iron balance and decreased SF levels along with a significant decrease in LIC. Another Phase II trial, including 184 patients with Diamond-Blackfan anemia, MDS, $\beta$-thalassemia, or other rare anemias, showed that DFX is effective for reducing iron burden in patients with various transfusion-dependent anemias. ${ }^{48}$ LIC changes were overall dependent on DFX dose and transfusional iron intake. There were no statistically significant differences in LIC changes between different disease groups. The ESCALATOR study, a prospective, open-label study performed in the Middle East on patients with $\beta$-thalassemia, previously treated with DFP and/ or DFO, showed that appropriate dosing of DFX controlled iron levels in population of patients with heavy iron load. ${ }^{49} \mathrm{~A}$ retrospective pooled analysis of patients with TDT and other transfusion-dependent diseases concluded that DFX therapy at doses greater than $30 \mathrm{mg} / \mathrm{kg}$ /day effectively reduced SF to levels lower than those prior to dose escalation with no safety concern. ${ }^{50}$ Looking further into the effect of DFX on the liver, Deugnier et al showed that DFX therapy for at least 3 years reversed or stabilized liver fibrosis in TDT patients with transfusional iron overload - an effect independent of exposure to hepatitis $\mathrm{C}$ virus and of reduction in LIC. ${ }^{51}$ The prospective 1-year EPIC study, including patients with transfusional iron overload secondary to thalassemia, MDS, aplastic anemia, sickle-cell disease, and other conditions, supported initial DFX doses based on transfusional iron intake with subsequent dose titration guided by SF and safety markers. ${ }^{52}$ The recommended initial dose was $20 \mathrm{mg} / \mathrm{kg} /$ day for patients receiving 2-4 pRBC units per month. DFX at a dose of $10 \mathrm{mg} / \mathrm{kg} /$ day or $30 \mathrm{mg} / \mathrm{kg} /$ day was recommended for patients receiving, respectively, less or more frequent transfusions. ${ }^{52} \mathrm{~A}$ substudy of the EPIC trial showed that DFX doses of $20 \mathrm{mg} / \mathrm{kg} /$ day safely maintained LIC $<7 \mathrm{mg} \mathrm{Fe} / \mathrm{g} \mathrm{dw} .{ }^{53}$ Doses of $30 \mathrm{mg} /$ $\mathrm{kg} /$ day were required for net iron reduction in patients with $\mathrm{LIC} \geq 7 \mathrm{mg} \mathrm{Fe} / \mathrm{g} \mathrm{dw}$. An extension of the EPIC cardiac substudy, which recruited 71 patients, concluded that 3 years of DFX treatment significantly decreased cardiac iron overload, as compared to baseline, and normalized T2* in $68.1 \%$ of patients with $\mathrm{T} 2 *$ between $10 \mathrm{~ms}$ and $<20 \mathrm{~ms} .{ }^{54}$ More recently, data from the CORDELIA study showed the non-inferiority of DFX compared with DFO for myocardial iron removal in 197 TDT patients with myocardial siderosis but no signs of cardiac dysfunction. ${ }^{55}$ The most common adverse events with DFX therapy include gastrointestinal disturbances, rash, and mild increases in serum creatinine. ${ }^{34,42}$ DFX therapy is not commonly associated with agranulocytosis and growth failure. ${ }^{47}$ DFX may be rarely associated with renal impairment, hepatic impairment, and gastrointestinal hemorrhage. ${ }^{42}$

\section{Combining iron chelators Combination and alternating therapy with DFO and DFP}

Combination therapy with DFO and DFP was introduced as a means to manage iron overload in patients suboptimally 
chelated with maximum doses of DFP. ${ }^{56}$ The synergistic effect of DFP and DFO on iron balance and urine iron excretion has been explained by the shuttle mechanism. DFP enters cells and removes iron, and then passes it on to DFO for excretion in urine or feces. ${ }^{57-59}$ Subsequently, DFP becomes free again to enter the cell and remove more iron. In the treatment of cardiac iron overload, evidence from well-conducted randomized controlled trials shows superior efficacy of DFP versus DFO, the superiority of combined DFP + DFO versus DFO alone, and the equivalence of DFX versus DFO. ${ }^{60}$

Earlier studies suggested a potential role for combination therapy with DFO and DFP showing that DFO + DFP is as effective as DFO in reducing iron load in both the adult and pediatric populations. ${ }^{61-63}$ This is especially important from the standpoint of compliance with treatment. Aydinok et al compared daily monotherapy with DFP (75 mg/kg/day), monotherapy with DFO (40-50 mg/kg/day for 5 days per week), and combination therapy with DFP (75 mg/kg/day for 7 days per week) + DFO (40-50 mg/kg/day for 2 days per week). ${ }^{64}$ The patients treated with DFP + DFO showed the highest total iron excretion and iron balance with results reaching statistical significance against DFP monotherapy and DFO monotherapy. In a randomized trial comparing DFO monotherapy, DFP monotherapy, and combination therapy with DFP + DFO, the change in LIC was not statistically significantly different between the different arms, suggesting that twice weekly administration of DFO in combination with DFP is a reasonable alternative regimen to continuous DFO monotherapy. ${ }^{65}$ Lai et al demonstrated that in TDT patients with well-established cardiac disease, therapy with $\mathrm{DFO}+\mathrm{DFP}$ is superior to DFO monotherapy. ${ }^{66}$ In addition to advances in assessment of cardiac iron load, the new chelation regimes have been suggested to contribute significantly to the reduction in cardiac morbidity and mortality in patients with TDT. ${ }^{67}$ For instance, switching from DFO to combination therapy with DFO + DFP was shown to prevent iron overload-related deaths. ${ }^{68}$ Combination therapy with DFO + DFP has also been shown to have favorable effects on cardiac iron load as assessed by T2* MRI and left ventricular ejection fraction. ${ }^{69,70}$ Farmaki et al also showed that intensive combined chelation normalized thalassemic patients' iron load, as assessed by cardiac T2* MRI, SF, and LIC. ${ }^{71}$ This approach also prevented and reversed cardiac and multiple endocrine complications. ${ }^{71}$ Therefore, the combination of $\mathrm{DFP}+\mathrm{DFO}$ is one of the most helpful available means of decreasing cardiac siderosis. The combination should be used, whenever deemed possible, in patients with significant cardiac iron loading. ${ }^{72}$
Alternating therapy with DFP (25 $\mathrm{mg} / \mathrm{kg}$ three times daily for 5 days per week) + DFO has been suggested to be at least as effective as DFO monotherapy in controlling iron overload in patients with TDT. ${ }^{73}$ Moreover, Abdelrazik showed that alternating DFP $(75 \mathrm{mg} / \mathrm{kg}$ /day for 4 days per week) + DFO (40 mg/kg/day for 2 days per week) resulted in significant improvement in SF and urinary iron excretion as compared to DFO monotherapy. ${ }^{74} \mathrm{~A}$ trial by Maggio et al showed that, compared with DFP $(75 \mathrm{mg} / \mathrm{kg} /$ day) alone, alternating treatment with DFP (75 mg/kg/day for 4 days per week) + DFO (50 mg/ $\mathrm{kg} /$ day day for 3 days per week) significantly decreased SF concentration during treatment for 5 years without significant differences in terms of survival, adverse events, and costs. ${ }^{75}$ This study compared DFP alone at $75 \mathrm{mg} / \mathrm{kg}$ versus DFP at $75 \mathrm{mg} /$ $\mathrm{kg}$ for 4 days per week and DFO by subcutaneous infusion (8-12 hours) at $50 \mathrm{mg} / \mathrm{kg}$ per day for the remaining 3 days per week.

Although the use of different scheduling regimens complicates comparisons among trials, a meta-analysis of LIC at the end of interventional studies favored combination therapy with DFP + DFO as compared to monotherapy with DFP. ${ }^{76}$ Safety analyses demonstrated no adverse events with DFP + DFO significantly different than those associated with monotherapy with each of DFP and DFO. ${ }^{76,77}$

\section{Combination of DFO and DFX}

A gerbil animal model study failed to produce any noticeable effect of the combined therapy with DFO and DFX above DFX monotherapy in either the liver or heart. Although combined therapy was well tolerated, its efficacy could not be established due to limitations in the animal model. ${ }^{78}$ In the clinical realm, in 2011, Voskaridou et al reported the first case of a patient with TDT successfully and safely treated with a combination of DFX and DFO. ${ }^{79}$ A pilot study, involving 14 patients with TDT and significant iron overload, showed that LIC significantly and safely improved after a median follow-up of 29 weeks. ${ }^{80}$ Grady et al used 34-day metabolic iron balance studies in six patients to evaluate monotherapy with DFX (30 mg/kg/day) versus monotherapy with DFO (40 mg/kg/day) versus combination therapy with DFX (30 mg/kg/day) and DFO (40 mg/kg/day). ${ }^{81}$ They determined that supplementing the daily use of DFX with 2-3 days of DFO therapy would place all patients into net negative iron balance. Similarly, Lal et al ran a pilot clinical trial to evaluate the safety and efficacy of combined therapy with DFX (20-30 mg/kg/day) and DFO (35-50 mg/kg on 3-7 days/week) in 22 patients with persistent iron overload or 
organ damage. ${ }^{82}$ In the 18 patients who completed the study, SF, LIC, and cardiac iron load significantly decreased proving that simultaneous administration of DFO and DFX rapidly reduced systemic and myocardial iron without increase in toxicity. ${ }^{82}$ Cassinerio et al also studied the efficacy and safety of combined DFX and DFO in 10 TDT patients. ${ }^{83} \mathrm{On}$ 1-year follow-up, there was an improvement in LIC, SF, and cardiac T2* MRI, although results did not reach statistical significance. The Hyperion trial (NCT01254227) evaluated the efficacy and safety of the combination therapy with DFX + DFO, followed by monotherapy with DFX in patients with severe transfusional cardiac siderosis. ${ }^{84}$ Despite a high attrition rate, the study showed that cardiac T2* improved during 12 months of treatment with DFX + DFO with side effect profiles comparable to adverse events encountered in monotherapy. ${ }^{84}$

\section{Combination and alternating therapy with DFP and DFX}

Combined chelation with DFP and DFX has been the subject of several ongoing or completed unpublished studies. ${ }^{85-87}$ Cases of successful and safe use of this combination have been reported. Voskaridou et al successfully used a combination of $75 \mathrm{mg} / \mathrm{kg}$ /day of DFP with $30 \mathrm{mg} / \mathrm{kg} /$ day of DFX in a thalassemic woman with iron overload refractory to DFX monotherapy. ${ }^{88}$ Combination therapy with DFX and DFP resulted in normalization of cardiac and liver T2* values with a considerable decrease in SF.

Alternating therapy with DFP and DFX has also been reported in two patients, who refused or had adverse effects with DFO, with improvement in LIC and SF. ${ }^{89}$ More welldesigned studies are needed to assess the efficacy and the safety of the combination of DFP and DFX.

\section{Starting and adjusting chelation therapy: what do the guidelines say?}

The guidelines governing ICT initiation and adjustment vary slightly depending on the panel of experts writing the recommendations. In our review, we discuss the guidelines from the following countries: Australia, Canada, Italy, the UK, and the US. ${ }^{90-95} \mathrm{We}$ also discuss the recent guidelines issued by the Thalassaemia International Federation (TIF) in 2014. ${ }^{96}$ The choice of the most appropriate chelation regimen depends on the iron burden, patient preference, the compliance to treatment, and toxicity of ICT. Multiple strategies based on SF, cardiac T2*, hepatic iron concentration, and transfusional iron burden have been suggested. All guidelines reviewed highlight the limitations of liver biopsy for assessment of hepatic liver concentration due to its invasiveness. ${ }^{95}$ Therefore, as a non-invasive means to assess LIC, MRI remains a reliable tool in the diagnosis of hepatic iron load..$^{91-96}$

Concerning the indication to initiate ICT, most guidelines agree that ICT should be started after the cumulative transfusion of 10-20 units of $\mathrm{pRBC}$ or when SF is greater than $1,000 \mathrm{ng} / \mathrm{mL} .{ }^{91,92,94,96}$ However, the Canadian, Italian, and US guidelines add LIC as a criterion to initiate ICT recommending ICT when LIC exceeds $7 \mathrm{mg} / \mathrm{g}$ dw or the upper limit of normal. ${ }^{90,92,93}$ Table 2 summarizes the recommendations of the different guidelines for monitoring the efficacy of ICT.

\section{TIF guidelines}

The most recent guidelines, published by TIF in 2014, recommend using DFO at a dose of $20-40 \mathrm{mg} / \mathrm{kg} /$ day five to seven times per week as a first line in children of age 2-6 years. ${ }^{96}$ In the latter group of patients, DFX $(20-40 \mathrm{mg} / \mathrm{kg} /$ day $)$ may be used as first line in US and as second line in Europe when

Table 2 Monitoring ICT for efficacy

\begin{tabular}{|c|c|c|c|c|c|}
\hline & Australia 94,95 & Canada ${ }^{93,95}$ & UK $^{91,95}$ & US $^{92,95}$ & Italy 90,95 \\
\hline SF & Q3 months & Q3 months & Q3 months & $\begin{array}{l}\text { If } \mathrm{SF} \text { I,000- } 2,500 \mathrm{ng} / \mathrm{mL} \rightarrow \mathrm{Q} 3 \text { months } \\
\text { If } \mathrm{SF}>2500 \mathrm{ng} / \mathrm{mL} \text { or cardiac } \\
\mathrm{T} 2 *<20 \mathrm{~ms} \text { without cardiac } \\
\text { dysfunction } \rightarrow \mathrm{Q} 2-3 \text { months }\end{array}$ & Serial SF \\
\hline LIC & $\begin{array}{l}\text { If normal } \rightarrow \text { Q2 yrs } \\
\text { If abnormal } \rightarrow \text { Q I yr } \\
\text { If }>15 \mathrm{mg} / \mathrm{g} \mathrm{dw} \rightarrow \text { Q6 months }\end{array}$ & QI-2 yr & $\begin{array}{l}\text { QI yr (assess more } \\
\text { frequently if necessary) }\end{array}$ & $\begin{array}{l}\text { If LIC }>7 \mathrm{mg} / \mathrm{g} \mathrm{dw} \rightarrow \mathrm{Q} 6 \text { months } \\
\text { If cardiac T2* }<20 \mathrm{~ms} \text { without } \\
\text { cardiac dysfunction } \rightarrow \text { Q6 months }\end{array}$ & QI yr \\
\hline $\begin{array}{l}\text { Cardiac } \\
\text { T2* }\end{array}$ & $\begin{array}{l}\text { If }<10 \text { ms or if cardiac } \\
\text { disease } \rightarrow \text { Q6 months } \\
\text { Otherwise } \rightarrow \text { Q I yr }\end{array}$ & $\begin{array}{l}\text { If }>20 \mathrm{~ms} \\
\rightarrow \mathrm{Q} \text { I- } 2 \mathrm{yr} \\
\text { If }<20 \mathrm{~ms} \\
\rightarrow \mathrm{Q} 6 \text { months }\end{array}$ & $\begin{array}{l}\text { If }>20 \mathrm{~ms} \rightarrow \mathrm{Q} 2 \mathrm{yr} \\
\text { If } 10-20 \mathrm{~ms} \rightarrow \mathrm{Q} 1 \mathrm{yr} \\
\text { If }<10 \mathrm{~ms} \text { with no cardiac } \\
\text { dysfunction } \rightarrow \mathrm{Q} 6 \text { months } \\
\text { If }<10 \mathrm{~ms} \text { with cardiac } \\
\text { dysfunction } \rightarrow \mathrm{Q} 3 \text { months }\end{array}$ & $\begin{array}{l}\text { Monitor cardiac function } \\
\text { within } 6 \text { months }\end{array}$ & $\begin{array}{l}\text { QI yr if } \\
\text { suboptimal } \\
\text { control of } \\
\text { LIC }\end{array}$ \\
\hline
\end{tabular}

Abbreviations: ICT, iron chelation therapy; SF, serum ferritin; Q, every; LIC, liver iron concentration; yr, year; dw, dry weight. 
therapy with DFO is inadequate or contraindicated. The same recommendations apply for children older than 6 years and adults, except that the dose of DFO may reach $60 \mathrm{mg} / \mathrm{kg}$ / day. Moreover, in patients older than 6 years, DFP may be used at $75-100 \mathrm{mg} / \mathrm{kg} /$ day if other agents are not tolerated or effective. The TIF guidelines also recommend intensive 24-hour therapy with DFO (50-60 mg/kg/day) in case of a persistently high SF or LIC $>15 \mathrm{mg} / \mathrm{g}$ dw. Significant heart disease may be treated by intensive DFO therapy or combination therapy with DFP + DFO.

\section{Other guidelines}

According to the Australian guidelines, initial therapy depends on the age of the patient. ${ }^{94}$ Notably, in the context of cardiac dysfunction, the Australian guidelines recommend the use of intravenous or subcutaneous DFO or combination therapy with DFO + DFP. The recommendations are summarized in Figure 3.

According to the Canadian guidelines, DFO, DFP, or DFX can be used at different doses depending on cardiac $\mathrm{T} 2 *$ if SF is between $1,000 \mathrm{ng} / \mathrm{mL}$ and $2,500 \mathrm{ng} / \mathrm{mL}$ or LIC is between $7 \mathrm{mg} / \mathrm{d} \mathrm{dw}$ and $15 \mathrm{mg} / \mathrm{d} \mathrm{dw}$, in the absence of cardiac dysfunction. ${ }^{93}$ However, DFO at doses $>50 \mathrm{mg} / \mathrm{kg} /$ day and combination therapy with DFO + DFP should be used if $\mathrm{SF}>2,500 \mathrm{ng} / \mathrm{mL}, \mathrm{LIC}>15 \mathrm{mg} / \mathrm{d} \mathrm{dw}$, cardiac T2* $<10 \mathrm{~ms}$, or cardiac dysfunction is present. The recommendations are summarized in Figure 4.
The US guidelines recommend maintaining existing ICT as long as LIC is between $3 \mathrm{mg} / \mathrm{dw}$ and $7 \mathrm{mg} / \mathrm{dw}$ and SF is between $1,000 \mathrm{ng} / \mathrm{mL}$ and 2,500 $\mathrm{ng} / \mathrm{mL} .{ }^{92}$ They endorse the use of DFX at maximum tolerated dose or DFO administered over 12 hours daily if cardiac T2* is between $10 \mathrm{~ms}$ and $20 \mathrm{~ms}$ in the absence of cardiac dysfunction. ${ }^{92}$ In the context of cardiac dysfunction or a cardiac $\mathrm{T} 2 *<10 \mathrm{~ms}$, the US guidelines recommend the continuous use of DFO over 24 hours daily. The recommendations are summarized in Figure 5.

The UK guidelines recommend using DFP as the firstline therapy if cardiac T2* $<20 \mathrm{~ms}, \mathrm{LIC}$ is between $2 \mathrm{mg} / \mathrm{g}$ $\mathrm{dw}$ and $7 \mathrm{mg} / \mathrm{g} \mathrm{dw}$, and $\mathrm{SF}$ is between $500 \mathrm{ng} / \mathrm{mL}$ and $1,500 \mathrm{ng} / \mathrm{mL} .{ }^{91} \mathrm{DFO}$ remains the recommended first-line treatment if cardiac T2* $>20 \mathrm{~ms}$, while DFX is reserved for patients non-adherent to DFO. DFP is used as a secondline agent in this context. The different treatment strategies when $\mathrm{LIC}>7 \mathrm{mg} / \mathrm{g} \mathrm{dw}$ or $\mathrm{SF}>1,500 \mathrm{ng} / \mathrm{mL}$ are depicted in Figure 6.

The Italian guidelines recommend DFO for children younger than 6 years. For patients with severe iron overload, evidenced by a SF $>3,000 \mathrm{ng} / \mathrm{mL}$ for 3 months, LIC $>15 \mathrm{mg} / \mathrm{g} \mathrm{dw}$, cardiac T2 $*<12 \mathrm{~ms}$, or cardiac dysfunction, intensive chelation with DFO or combination therapy with DFP + DFO is recommended. ${ }^{90}$ Otherwise, for moderate iron overload, DFO remains the first-line agent, while DFX is used in patients with intolerance or non-compliance to DFO

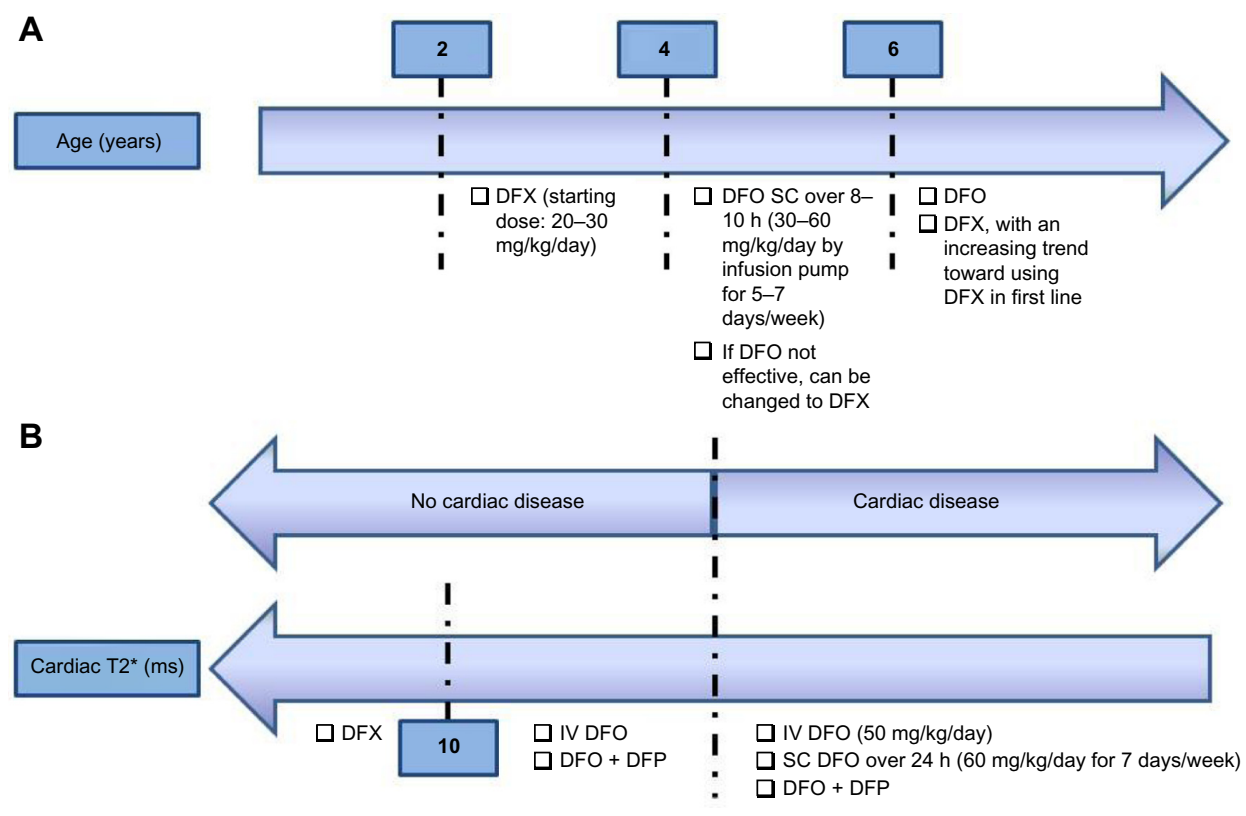

Figure 3 The figure summarizes the Australian practice guidelines in treating transfusional iron overload in TDT.

Notes: (A) Describes the different choices of iron chelators depending on age. (B) Summarizes the recommendations for iron chelation therapy based on cardiac disease status and cardiac T2*.

Abbreviations: TDT, transfusion-dependent thalassemia; DFX, deferasirox; DFO, deferoxamine; h, hour; DFP, deferiprone; SC, subcutaneously. 


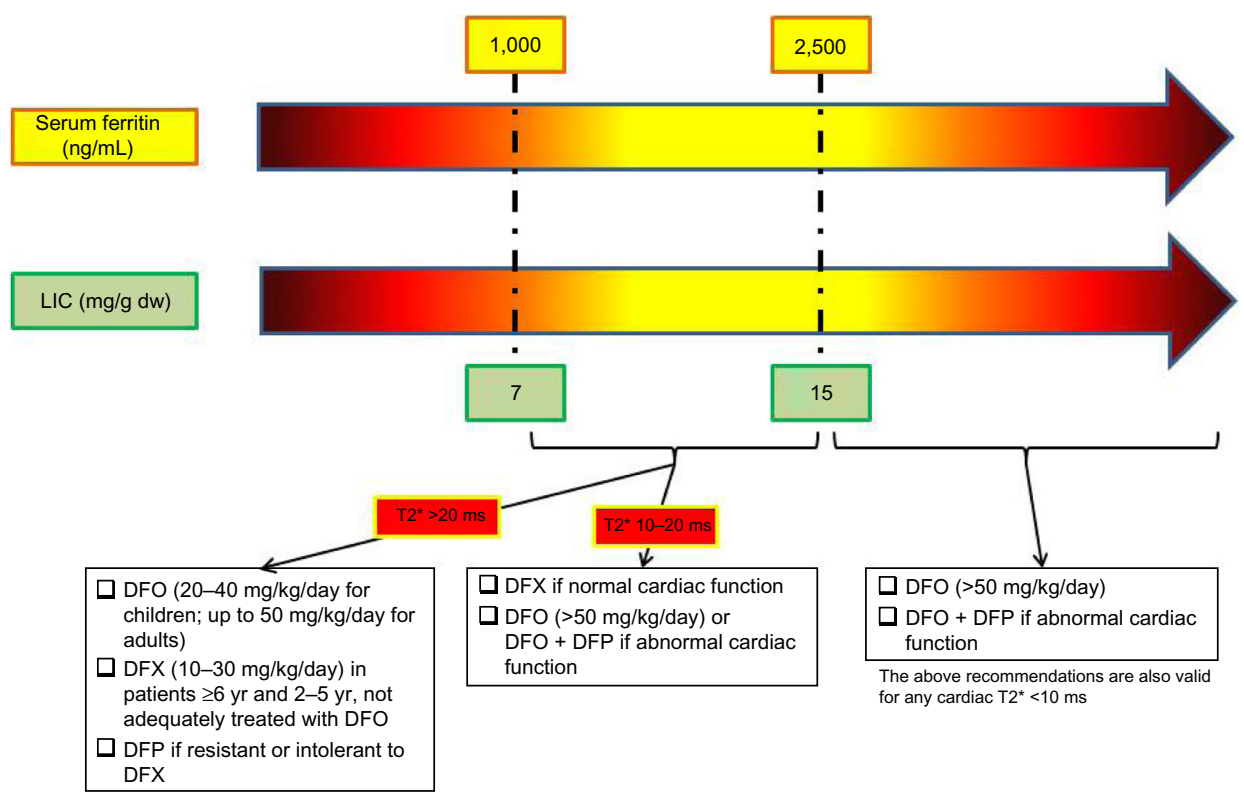

Figure 4 The figure summarizes the Canadian practice guidelines in treating transfusional iron overload in TDT.

Abbreviations: TDT, transfusion-dependent thalassemia; LIC, liver iron concentration; dw, dry weight; DFO, deferoxamine; DFX, deferasirox; yr, year; DFP, deferiprone.

in the absence of severe iron overload. DFP is reserved for patients who are resistant or intolerant to DFX. Finally, the Italian guidelines recommend DFO for children younger than 6 years. For patients with severe iron overload, evidenced by a SF $>3,000 \mathrm{ng} / \mathrm{mL}$ for 3 months, LIC $>15 \mathrm{mg} / \mathrm{g} \mathrm{dw}$, cardiac $\mathrm{T} 2 *<12 \mathrm{~ms}$, or cardiac dysfunction, intensive chelation with DFO or combination therapy with DFP + DFO is recommended.$^{90}$ Otherwise, for moderate iron overload, DFO remains the first-line agent, while DFX is used in patients with intolerance or non-compliance to DFO in the absence of severe iron overload. DFP is reserved for patients who are resistant or intolerant to DFX.

\section{Future directions in treating iron overload}

In 2000, Modell et al argued that about $50 \%$ of UK patients with $\beta$-thalassemia major die before the age of 35 years, mainly because conventional iron-chelation therapy is too burdensome for full adherence. Patients require an individually tailored treatment plan incorporating new, more tolerable

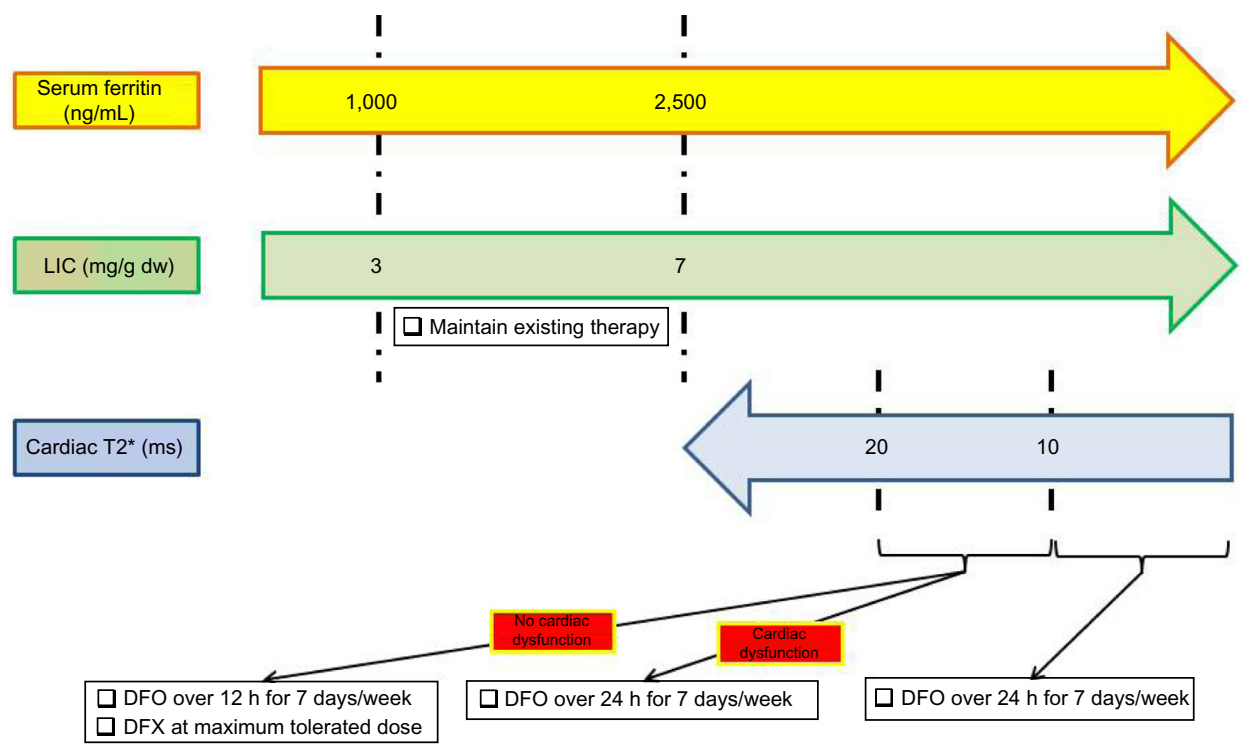

Figure $\mathbf{5}$ The figure summarizes the US practice guidelines in treating transfusional iron overload in TDT.

Abbreviations: TDT, transfusion-dependent thalassemia; LIC, liver iron concentration; dw, dry weight; DFO, deferoxamine; h, hour; DFX, deferasirox. 


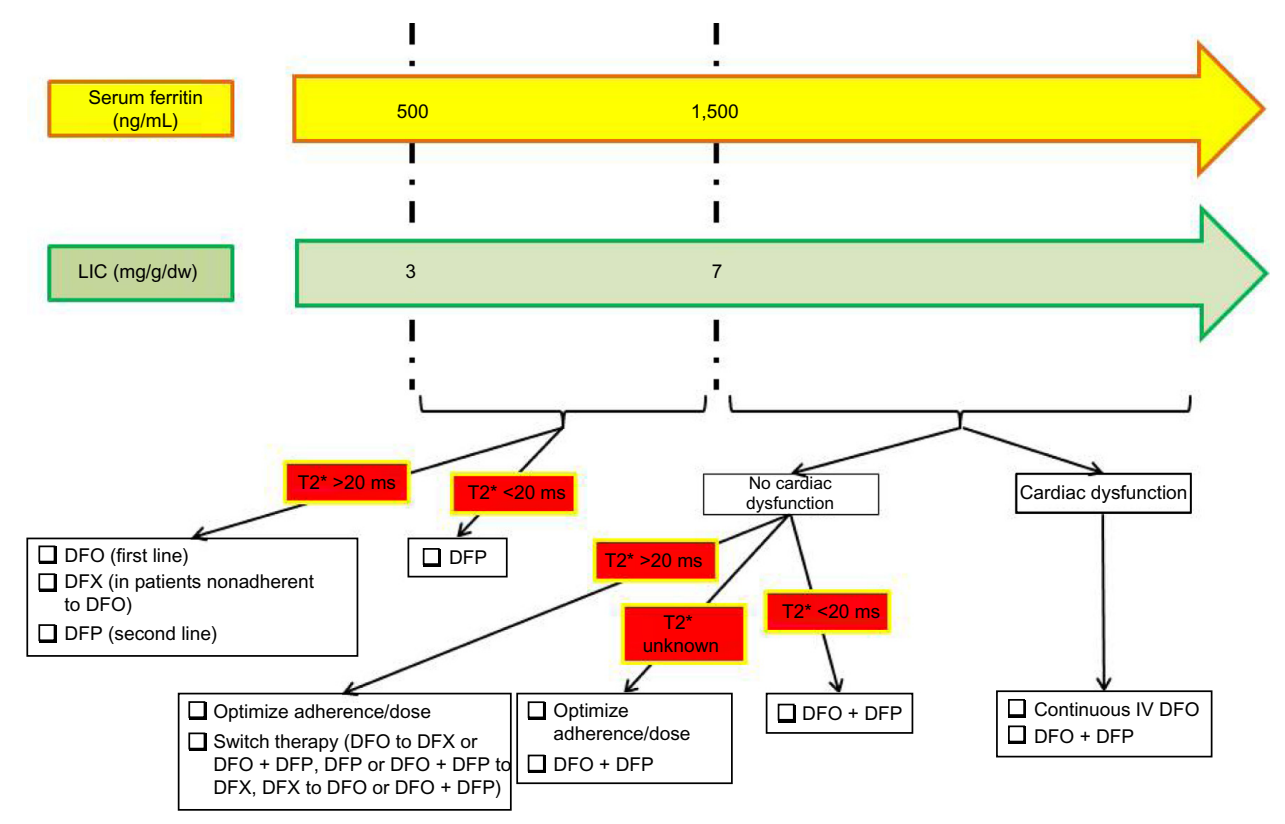

Figure 6 The figure summarizes the UK practice guidelines in treating transfusional iron overload in TDT.

Abbreviations: TDT, transfusion-dependent thalassemia; LIC, liver iron concentration; dw, dry weight; DFO, deferoxamine; DFX, deferasirox; DFP, deferiprone.

approaches. ${ }^{97}$ Advancing the treatment of transfusional iron overload includes not only pharmacologically improving iron chelators and tailoring chelation regimens through combining or alternating agents but also optimizing the treatment of the underlying disorder and, hence, decreasing the need for transfusions. An ideal iron chelator would have high iron chelating efficiency, high oral availability, tolerable profile of adverse events, once-daily dosing, palatable formulation, and high penetration into organs with iron deposition. Challenges in trial design in the realm of iron chelation include the small number of patients with conditions requiring chronic transfusions and the difficulty to recruit subjects to the parenteral arm in head-to-head trials involving DFO.

\section{Innovation in chelation: improving the available chelators}

Most attempts at improving drug administration, compliance, and palatability involve DFX. A single-arm study involving pediatric and adult patients with transfusional iron overload showed that additional administration options for DFX appeared to improve palatability ratings and GI tolerability. ${ }^{43}$ Taking crushed DFX with soft food at breakfast time seemed to result in the highest palatability ratings. ${ }^{43} \mathrm{~A}$ Phase II study (NCT02125877) investigating the benefits of a film-coated tablet of DFX, as opposed to a dispersible tablet, is currently ongoing and recruiting patients of age 10 years or older with TDT or MDS with resultant iron overload..$^{98}$ As for DFP, there have been studies on the pharmacokinetic profiles of a single dose of a sustained-release formulation without any published data. ${ }^{99,100}$

\section{Innovation in chelation: a novel agent}

A novel oral iron chelator SP-420, which showed efficacy in models of iron overload, has been associated with reduced renal toxicity in exploratory studies. ${ }^{101-103}$ It is currently being studied in a Phase Ib trial. ${ }^{104}$ Other clinical studies involving the oral chelator FBS0701, a member of the desazadesferrithiocin class, have been terminated despite the completion of initial pharmacokinetic and pharmacodynamic studies. ${ }^{105}$

\section{Hitting a step earlier: decreasing transfusional iron burden}

Decreasing the need or the frequency of blood transfusions is one way of addressing the issue of iron overload. Agents that might be promising to decrease the transfusional requirements include those that target ineffective hematopoiesis, such as JAK2 inhibitors, and those that appear to limit the overproduction of immature erythroid cells in thalassemia patients, potentially reversing extra-medullary hematopoiesis and preventing splenectomy and sotatercept (ACE-011) that appear to function by blocking the activity of certain TGF- $\beta$ family cytokines involved in late stages of erythropoiesis, eventually leading to an increase in hemoglobin production in these patients. ${ }^{106,107}$

As a conclusion, it is imperative that, as new evidence becomes available from ongoing research on novel agents 
and as more experience is gained from the use of the available iron chelators, clinical practice guidelines, being evidence-based, should be updated to suit the clinical goals of care in TDT.

\section{Disclosure}

Antoine N Saliba and Afif Harb have no conflicts of interest to declare. Ali Taher receives research funding and honoraria from Novartis Pharmaceuticals.

\section{References}

1. Pietrangelo A. Physiology of iron transport and the hemochromatosis gene. Am J Physiol Gastrointest Liver Physiol. 2002;282(3): G403-G414.

2. Knutson M, Wessling-Resnick M. Iron metabolism in the reticuloendothelial system. Crit Rev Biochem Mol Biol. 2003;38(1):61-88.

3. Hoffbrand AV, Taher A, Cappellini MD. How I treat transfusional iron overload. Blood. 2012;120(18):3657-3669.

4. Fillet G, Beguin Y, Baldelli L. Model of reticuloendothelial iron metabolism in humans: abnormal behavior in idiopathic hemochromatosis and in inflammation. Blood. 1989;74(2):844-851.

5. Breuer W, Hershko C, Cabantchik ZI. The importance of nontransferrin bound iron in disorders of iron metabolism. Transfus Sci. 2000;23(3):185-192.

6. Nemeth E, Tuttle MS, Powelson J, et al. Hepcidin regulates cellular iron efflux by binding to ferroportin and inducing its internalization. Science. 2004;306(5704):2090-2093.

7. Nemeth E. Iron regulation and erythropoiesis. Curr Opin Hematol. 2008;15(3):169-175

8. Tanno T, Porayette P, Sripichai O, et al. Identification of TWSG1 as a second novel erythroid regulator of hepcidin expression in murine and human cells. Blood. 2009;114(1):181-186.

9. Tanno T, Bhanu NV, Oneal PA, et al. High levels of GDF15 in thalassemia suppress expression of the iron regulatory protein hepcidin. Nat Med. 2007;13(9):1096-1101.

10. Tanno T, Rabel A, Lee YT, Yau YY, Leitman SF, Miller JL. Expression of growth differentiation factor 15 is not elevated in individuals with iron deficiency secondary to volunteer blood donation. Transfusion. 2010;50(7):1532-1535.

11. Casanovas G, Vujić Spasic M, Casu C, et al. The murine growth differentiation factor 15 is not essential for systemic iron homeostasis in phlebotomized mice. Haematologica. 2013;98(3):444-447.

12. Kautz L, Jung G, Valore EV, Rivella S, Nemeth E, Ganz T. Identification of erythroferrone as an erythroid regulator of iron metabolism. Nat Genet. 2014;46(7):678-684

13. Novartis. Desferal (Deferoxamine Mesylate) Prescribing Information. Switzerland: Novartis Pharmaceuticals; 2011.

14. Porter JB, Abeysinghe RD, Marshall L, Hider RC, Singh S. Kinetics of removal and reappearance of non-transferrin-bound plasma iron with deferoxamine therapy. Blood. 1996;88(2):705-713.

15. Barry M, Flynn DM, Letsky EA, Risdon RA. Long-term chelation therapy in thalassaemia major: effect on liver iron concentration, liver histology, and clinical progress. Br Med J. 1974;2(5909): $16-20$.

16. Modell B, Letsky EA, Flynn DM, Peto R, Weatherall DJ. Survival and desferrioxamine in thalassaemia major. $\mathrm{Br}$ Med $J .1982 ; 284(6322)$ : 1081-1084.

17. Borgna-Pignatti C, Rugolotto S, De Stefano P, et al. Survival and complications in patients with thalassemia major treated with transfusion and deferoxamine. Haematologica. 2004;89(10):1187-1193.

18. Brittenham GM, Griffith PM, Nienhuis AW, et al. Efficacy of deferoxamine in preventing complications of iron overload in patients with thalassemia major. N Engl J Med. 1994;331(9):567-573.
19. Anderson LJ, Westwood MA, Holden S, et al. Myocardial iron clearance during reversal of siderotic cardiomyopathy with intravenous desferrioxamine: a prospective study using T2* cardiovascular magnetic resonance. Br J Haematol. 2004;127(3):348-355.

20. Davis BA, Porter JB. Long-term outcome of continuous 24-hour deferoxamine infusion via indwelling intravenous catheters in high-risk beta-thalassemia. Blood. 2000;95(4):1229-1236.

21. Cohen A, Martin M, Mizanin J, Konkle DF, Schwartz E. Vision and hearing during deferoxamine therapy. $J$ Pediatr. 1990;117(2 pt 1): 326-330.

22. Olivieri NF, Buncic JR, Chew E, et al. Visual and auditory neurotoxicity in patients receiving subcutaneous deferoxamine infusions. $N$ Engl $J$ Med. 1986;314(14):869-873.

23. Cohen AR, Galanello R, Pennell DJ, Cunningham MJ, Vichinsky E. Thalassemia. Hematology Am Soc Hematol Educ Program. 2004;1: 14-34.

24. Delea TE, Edelsberg J, Sofrygin O, et al. Consequences and costs of noncompliance with iron chelation therapy in patients with transfusiondependent thalassemia: a literature review. Transfusion. 2007;47(10): 1919-1929.

25. Agency EM. Ferriprox: EPAR - Product Information; 2009. Available from: http://www.ema.europa.eu/docs/en_GB/document_library/EPAR__Product_Information/human/000236/WC500022050.pdf, 2014.

26. Traynor K. Deferiprone approved for iron overload. Am J Health Syst Pharm. 2011;68(22):2106.

27. Borgna-Pignatti C, Cappellini MD, De Stefano P, et al. Cardiac morbidity and mortality in deferoxamine- or deferiprone-treated patients with thalassemia major. Blood. 2006;107(9):3733-3737.

28. Piga A, Gaglioti C, Fogliacco E, Tricta F. Comparative effects of deferiprone and deferoxamine on survival and cardiac disease in patients with thalassemia major: a retrospective analysis. Haematologica. 2003;88(5):489-496.

29. Addis A, Loebstein R, Koren G, Einarson TR. Meta-analytic review of the clinical effectiveness of oral deferiprone (L1). Eur J Clin Pharmacol. 1999;55(1):1-6.

30. Maggio A, D'Amico G, Morabito A, et al. Deferiprone versus deferoxamine in patients with thalassemia major: a randomized clinical trial. Blood Cells Mol Dis. 2002;28(2):196-208.

31. Taher A, Sheikh-Taha M, Sharara A, et al. Safety and effectiveness of $100 \mathrm{mg} / \mathrm{kg} /$ day deferiprone in patients with thalassemia major: a twoyear study. Acta Haematol. 2005;114(3):146-149.

32. Anderson LJ, Wonke B, Prescott E, Holden S, Walker JM, Pennell DJ. Comparison of effects of oral deferiprone and subcutaneous desferrioxamine on myocardial iron concentrations and ventricular function in beta-thalassaemia. Lancet. 2002;360(9332):516-520.

33. Pennell DJ, Berdoukas V, Karagiorga M, et al. Randomized controlled trial of deferiprone or deferoxamine in beta-thalassemia major patients with asymptomatic myocardial siderosis. Blood. 2006;107(9): 3738-3744.

34. Berdoukas V, Chouliaras G, Moraitis P, Zannikos K, Berdoussi E, Ladis $\mathrm{V}$. The efficacy of iron chelator regimes in reducing cardiac and hepatic iron in patients with thalassaemia major: a clinical observational study. J Cardiov Magn Reson. 2009;11:20.

35. Pennell DJ, Carpenter JP, Roughton M, Cabantchik Z. On improvement in ejection fraction with iron chelation in thalassemia major and the risk of future heart failure. J Cardiov Magn Reson. 2011;13:45.

36. Maggio A, Vitrano A, Capra M, et al. Improving survival with deferiprone treatment in patients with thalassemia major: a prospective multicenter randomised clinical trial under the auspices of the Italian Society for Thalassemia and Hemoglobinopathies. Blood Cells Mol Dis. 2009;42(3):247-251.

37. Cohen AR, Galanello R, Piga A, De Sanctis V, Tricta F. Safety and effectiveness of long-term therapy with the oral iron chelator deferiprone. Blood. 2003;102(5):1583-1587.

38. Olivieri NF, Brittenham GM, McLaren CE, et al. Long-term safety and effectiveness of iron-chelation therapy with deferiprone for thalassemia major. N Engl J Med. 1998;339(7):417-423. 
39. Wu SF, Peng CT, Wu KH, Tsai CH. Liver fibrosis and iron levels during long-term deferiprone treatment of thalassemia major patients. Hemoglobin. 2006;30(2):215-218.

40. Wanless IR, Sweeney G, Dhillon AP, et al. Lack of progressive hepatic fibrosis during long-term therapy with deferiprone in subjects with transfusion-dependent beta-thalassemia. Blood. 2002;100(5):1566-1569.

41. Taher A, Aoun E, Sharara AI, et al. Five-year trial of deferiprone chelation therapy in thalassaemia major patients. Acta Haematol. 2004; 112(4):179-183

42. Exjade (deferasirox) [prescribing information]. Switzerland: Novartis Pharmaceuticals; 2005.

43. Goldberg SL, Giardina PJ, Chirnomas D, Esposito J, Paley C, Vichinsky E. The palatability and tolerability of deferasirox taken with different beverages or foods. Pediatr Blood Cancer. 2013;60(9): 1507-1512.

44. Séchaud R, Dutreix C, Balez S, et al. Relative bioavailability of deferasirox tablets administered without dispersion and dispersed in various drinks. Int J Clin Pharmacol Ther. 2008;46(2):102-108.

45. Piga A, Galanello R, Forni GL, et al. Randomized phase II trial of deferasirox (Exjade, ICL670), a once-daily, orally-administered iron chelator, in comparison to deferoxamine in thalassemia patients with transfusional iron overload. Haematologica. 2006;91(7):873-880.

46. Galanello R, Piga A, Forni GL, et al. Phase II clinical evaluation of deferasirox, a once-daily oral chelating agent, in pediatric patients with beta-thalassemia major. Haematologica. 2006;91(10):1343-1351.

47. Cappellini MD, Cohen A, Piga A, et al. A phase 3 study of deferasirox (ICL670), a once-daily oral iron chelator, in patients with betathalassemia. Blood. 2006;107(9):3455-3462.

48. Porter J, Galanello R, Saglio G, et al. Relative response of patients with myelodysplastic syndromes and other transfusion-dependent anaemias to deferasirox (ICL670): a 1-yr prospective study. Eur J Haematol. 2008;80(2):168-176.

49. Taher A, El-Beshlawy A, Elalfy MS, et al. Efficacy and safety of deferasirox, an oral iron chelator, in heavily iron-overloaded patients with beta-thalassaemia: the ESCALATOR study. Eur J Haematol. 2009;82(6):458-465.

50. Taher A, Cappellini MD, Vichinsky E, et al. Efficacy and safety of deferasirox doses of $>30 \mathrm{mg} / \mathrm{kg}$ per $\mathrm{d}$ in patients with transfusion-dependent anaemia and iron overload. Br J Haematol. 2009;147(5): 752-759.

51. Deugnier Y, Turlin B, Ropert M, et al. Improvement in liver pathology of patients with beta-thalassemia treated with deferasirox for at least 3 years. Gastroenterology. 2011;141(4):1202-1211, 1211. e1201-1203.

52. Cappellini MD, Porter J, El-Beshlawy A, EPIC Study Investigators, et al. Tailoring iron chelation by iron intake and serum ferritin: the prospective EPIC study of deferasirox in 1744 patients with transfusiondependent anemias. Haematologica. 2010;95(4):557-566.

53. Porter JB, Elalfy MS, Taher AT, et al. Efficacy and safety of deferasirox at low and high iron burdens: results from the EPIC magnetic resonance imaging substudy. Ann Hematol. 2013;92(2):211-219.

54. Pennell DJ, Porter JB, Cappellini MD, et al. Deferasirox for up to 3 years leads to continued improvement of myocardial $\mathrm{T} 2 *$ in patients with beta-thalassemia major. Haematologica. 2012;97(6):842-848.

55. Pennell DJ, Porter JB, Piga A, CORDELIA study investigators, et al. A 1-year randomized controlled trial of deferasirox vs deferoxamine for myocardial iron removal in beta-thalassemia major (CORDELIA). Blood. 2014;123(10):1447-1454.

56. Wonke B, Wright C, Hoffbrand AV. Combined therapy with deferiprone and desferrioxamine. Br J Haematol. 1998;103(2):361-364.

57. Breuer W, Ermers MJ, Pootrakul P, Abramov A, Hershko C, Cabantchik ZI. Desferrioxamine-chelatable iron, a component of serum non-transferrin-bound iron, used for assessing chelation therapy. Blood. 2001;97(3):792-798.

58. Link G, Konijn AM, Breuer W, Cabantchik ZI, Hershko C. Exploring the "iron shuttle" hypothesis in chelation therapy: effects of combined deferoxamine and deferiprone treatment in hypertransfused rats with labeled iron stores and in iron-loaded rat heart cells in culture. $J$ Lab Clin Med. 2001;138(2):130-138.
59. Evans P, Kayyali R, Hider RC, Eccleston J, Porter JB. Mechanisms for the shuttling of plasma non-transferrin-bound iron (NTBI) onto deferoxamine by deferiprone. Trans Res. 2010;156(2):55-67.

60. Pennell DJ, Udelson JE, Arai AE, American Heart Association Committee on Heart Failure and Transplantation of the Council on Clinical Cardiology and Council on Cardiovascular Radiology and Imaging, et al. Cardiovascular function and treatment in betathalassemia major: a consensus statement from the American Heart Association. Circulation. 2013;128(3):281-308.

61. Mourad FH, Hoffbrand AV, Sheikh-Taha M, Koussa S, Khoriaty AI, Taher A. Comparison between desferrioxamine and combined therapy with desferrioxamine and deferiprone in iron overloaded thalassaemia patients. Br J Haematol. 2003;121(1):187-189.

62. Gomber S, Saxena R, Madan N. Comparative efficacy of desferrioxamine, deferiprone and in combination on iron chelation in thalassemic children. Indian Pediatr. 2004;41(1):21-27.

63. Ha SY, Chik KW, Ling SC, et al. A randomized controlled study evaluating the safety and efficacy of deferiprone treatment in thalassemia major patients from Hong Kong. Hemoglobin. 2006;30(2): 263-274.

64. Aydinok Y, Ulger Z, Nart D, et al. A randomized controlled 1-year study of daily deferiprone plus twice weekly desferrioxamine compared with daily deferiprone monotherapy in patients with thalassemia major. Haematologica. 2007;92(12):1599-1606.

65. El-Beshlawy A, Manz C, Naja M, et al. Iron chelation in thalassemia: combined or monotherapy? The Egyptian experience. Ann Hematol. 2008;87(7):545-550.

66. Lai ME, Grady RW, Vacquer S, et al. Increased survival and reversion of iron-induced cardiac disease in patients with thalassemia major receiving intensive combined chelation therapy as compared to deferoxamine alone. Blood Cells Mol Dis. 2010;45(2):136-139.

67. Ladis V, Chouliaras G, Berdoukas V, et al. Relation of chelation regimes to cardiac mortality and morbidity in patients with thalassaemia major: an observational study from a large Greek Unit. Eur J Haematol. 2010;85(4):335-344.

68. Telfer PT, Warburton F, Christou S, et al. Improved survival in thalassemia major patients on switching from desferrioxamine to combined chelation therapy with desferrioxamine and deferiprone. Haematologica. 2009;94(12):1777-1778.

69. Tanner MA, Galanello R, Dessi C, et al. A randomized, placebocontrolled, double-blind trial of the effect of combined therapy with deferoxamine and deferiprone on myocardial iron in thalassemia major using cardiovascular magnetic resonance. Circulation. 2007;115(14): 1876-1884.

70. Tanner MA, Galanello R, Dessi C, et al. Combined chelation therapy in thalassemia major for the treatment of severe myocardial siderosis with left ventricular dysfunction. J Cardiov Magn Reson. 2008;10:12.

71. Farmaki K, Tzoumari I, Pappa C, Chouliaras G, Berdoukas V. Normalisation of total body iron load with very intensive combined chelation reverses cardiac and endocrine complications of thalassaemia major. Br J Haematol. 2010;148(3):466-475.

72. Kwiatkowski JL. Real-world use of iron chelators. Hematology Am Soc Hematol Educ Program. 2011;2011:451-458.

73. Galanello R, Kattamis A, Piga A, et al. A prospective randomized controlled trial on the safety and efficacy of alternating deferoxamine and deferiprone in the treatment of iron overload in patients with thalassemia. Haematologica. 2006;91(9):1241-1243.

74. Abdelrazik N. Pattern of iron chelation therapy in Egyptian beta thalassemic patients: Mansoura University Children's Hospital experience. Hematology. 2007;12(6):577-585.

75. Maggio A, Vitrano A, Capra M, et al. Long-term sequential deferipronedeferoxamine versus deferiprone alone for thalassaemia major patients: a randomized clinical trial. Br J Haematol. 2009;145(2):245-254.

76. Maggio A, Filosa A, Vitrano A, et al. Iron chelation therapy in thalassemia major: a systematic review with meta-analyses of 1520 patients included on randomized clinical trials. Blood Cells Mol Dis. 2011;47(3):166-175. 
77. Fisher SA, Brunskill SJ, Doree C, Gooding S, Chowdhury O, Roberts DJ. Desferrioxamine mesylate for managing transfusional iron overload in people with transfusion-dependent thalassaemia. The Cochrane Database of Syst Rev. 2013;8:Cd004450.

78. Otto-Duessel M, Brewer C, Gonzalez I, Nick H, Wood JC. Safety and efficacy of combined chelation therapy with deferasirox and deferoxamine in a gerbil model of iron overload. Acta Haematol. 2008;120(2):123-128.

79. Voskaridou E, Komninaka V, Karavas A, Terpos E, Akianidis V, Christoulas D. Combination therapy of deferasirox and deferoxamine shows significant improvements in markers of iron overload in a patient with beta-thalassemia major and severe iron burden. Transfusion. 2014;54(3):646-649.

80. Lal A, Sweeters N, Herz M, et al. Safety of combined chelation therapy with deferasirox and deferoxamine in transfusion-dependent thalassemia [Abstract]. Blood. 2009;114:2021.

81. Grady RW, Galanello R, Randolph RE, Kleinert DA, Dessi C, Giardina PJ. Toward optimizing the use of deferasirox: potential benefits of combined use with deferoxamine. Haematologica. 2013;98(1):129-135.

82. Lal A, Porter J, Sweeters N, et al. Combined chelation therapy with deferasirox and deferoxamine in thalassemia. Blood Cells Mol Dis. 2013;50(2):99-104.

83. Cassinerio E, Orofino N, Roghi A, et al. Combination of deferasirox and deferoxamine in clinical practice: an alternative scheme of chelation in thalassemia major patients. Blood Cells Mol Dis. 2014;53(3):164-167.

84. Aydinok Y, Kattamis A, Cappellini MD, et al. Deferasiroxdeferoxamine combination therapy reduces cardiac iron with rapid liver iron Removal in patients with severe transfusional iron overload (HYPERION). In: 55th ASH annual meeting; December 8, 2013; New Orleans, LA.

85. Combination Deferasirox and Deferiprone for Severe Iron Overload in Thalassemia; 2015. Available from: https://clinicaltrials.gov/ct2/show/ NCT01709032?term=Deferiprone+AND+deferasirox\&rank=1, 2015.

86. Study of Efficacy, Safety of Combined Deferasirox and Deferiprone Versus Combined Deferiprone and Desferal In Conditions of Iron Overload. 2015. Available from: https://clinicaltrials.gov/ct2/show/NC T01511848?term=Deferiprone + AND+deferasirox\&rank=3. Accessed 2015.

87. Clinical Trial of Deferasirox Combination Treatment with Deferiprone in Thalassaemia Patients; 2015. Available from: https:/clinicaltrials. gov/ct2/show/NCT02198508?term=Deferiprone+AND+deferasirox\& rank=4, 2015 .

88. Voskaridou E, Christoulas D, Terpos E. Successful chelation therapy with the combination of deferasirox and deferiprone in a patient with thalassaemia major and persisting severe iron overload after single-agent chelation therapies. Br J Haematol. 2011;154(5):654-656.

89. Balocco M, Carrara P, Pinto V, Forni GL. Daily alternating deferasirox and deferiprone therapy for "hard-to-chelate" beta-thalassemia major patients. Am J Hematol. 2010;85(6):460-461.

90. Angelucci E, Barosi G, Camaschella C, et al. Italian Society of Hematology practice guidelines for the management of iron overload in thalassemia major and related disorders. Haematologica. 2008;93(5): 741-752.

91. Yardumian A, Telfer P, Darbyshire P. Standards for the Clinical Care of Children and Adults with Thalassaemia in the UK. 2nd ed; 2008. Available from:http:/www.hbpinfo.com/ukts-standards-2008.pdf, 2015
92. Vichinsky E, Levine L. Standard-of-Care Clinical Practice Guidelines; 2012. Available from: http://thalassemia.com/treatment-guidelines-5. aspx\#gsc.tab=0, 2015.

93. Sayani F, Warner M, Wu J, Wong-Rieger D, Humphreys K, Odame I. Guidelines for the Clinical Care of Patients with Thalassemia in Canada. Nicosia, Cyprus: Thalassaemia International Federation; 2009.

94. Ho PJ, Tay L, Lindeman R, Catley L, Bowden DK. Australian guidelines for the assessment of iron overload and iron chelation in transfusion-dependent thalassaemia major, sickle cell disease and other congenital anaemias. Intern Med J. 2011;41(7):516-524.

95. Musallam KM, Angastiniotis M, Eleftheriou A, Porter JB. Cross-talk between available guidelines for the management of patients with beta-thalassemia major. Acta Haematol. 2013;130(2):64-73

96. Cappellini MD, Cohen A, Porter J, Taher A, Viprakasit V. Guidelines for the Management of Transfusion Dependent Thalassemia. 3rd ed. Nicosia, Cyprus: Thalassaemia International Federation; 2014.

97. Modell B, Khan M, Darlison M. Survival in beta-thalassaemia major in the UK: data from the UK Thalassaemia Register. Lancet 2000;355(9220):2051-2052.

98. Phase II Study to Investigate the Benefits of an Improved Deferasirox Formulation (Film-coated Tablet); 2015. Available from: https://clinicaltrials.gov/ct2/show/study/NCT02125877?term=Deferasirox\&rank $=30,2015$.

99. Pilot Study of the Pharmacokinetic Profile of a Single Dose of Deferiprone Sustained-Release Formulation in Healthy Volunteers; 2015. Available from: https://clinicaltrials.gov/ct2/show/NCT02189 941?term=deferiprone\&rank=5. Accessed 2015.

100. Absorption, Metabolism, and Excretion of a Single Dose of Ferriprox ${ }^{\circledR}$ in Patients With Sickle Cell Disease; 2015. Available from: https:// clinicaltrials.gov/ct2/show/study/NCT01835496?term=deferiprone \&rank=9. Accessed Jan 2015.

101. Bergeron RJ, Wiegand J, McManis JS, Bharti N, Singh S. Design, synthesis, and testing of non-nephrotoxic desazadesferrithiocin polyether analogues. J Med Chem. 2008;51(13):3913-3923.

102. Bergeron RJ, Wiegand J, Bharti N, McManis JS, Singh S. Desferrithiocin analogue iron chelators: iron clearing efficiency, tissue distribution, and renal toxicity. Biometals. 2011;24(2):239-258.

103. Bergeron RJ, Bharti N, Wiegand J, McManis JS, Singh S, Abboud KA The impact of polyether chain length on the iron clearing efficiency and physiochemical properties of desferrithiocin analogues. $J$ Med Chem. 2010;53(7):2843-2853.

104. Safety and Pharmacokinetic Study of Escalating Doses of $\mathrm{SP}-420$, an Iron Chelator, in Patients with $\beta$-Thalassemia; 2015. Available from: https://clinicaltrials.gov/ct2/show/record/ NCT02274233?term $=$ sp+420\&rank=1.

105. Rienhoff HY Jr, Viprakasit V, Tay L, et al. A phase 1 dose-escalation study: safety, tolerability, and pharmacokinetics of FBS0701, a novel oral iron chelator for the treatment of transfusional iron overload. Haematologica. 2011;96(4):521-525.

106. Suragani RN, Cawley SM, Li R, et al. Modified activin receptor IIB ligand trap mitigates ineffective erythropoiesis and disease complications in murine beta-thalassemia. Blood. 2014;123(25):3864-3872.

107. Dussiot M, Maciel TT, Fricot A, et al. An activin receptor IIA ligand trap corrects ineffective erythropoiesis in beta-thalassemia. Nat Med. 2014;20(4):398-407.

Journal of Blood Medicine

\section{Publish your work in this journal}

The Journal of Blood Medicine is an international, peer-reviewed, open access, online journal publishing laboratory, experimental and clinical aspects of all topics pertaining to blood based medicine including but not limited to: Transfusion Medicine; Blood collection, Donor issues, Transmittable diseases, and Blood banking logistics; Immunohematology; Artificial and alternative

blood based therapeutics; Hematology; Biotechnology/nanotechnology of blood related medicine; Legal aspects of blood medicine; Historical perspectives. The manuscript management system is completely online and includes a very quick and fair peer-review system. Visit http://www.dovepress.com/ testimonials.php to read real quotes from published authors.

\section{Dovepress}

